\title{
Cross-Modal Plasticity in Cuban Visually-Impaired Child Cochlear Implant Candidates: Topography of Somatosensory Evoked Potentials
}

\author{
Lidia E. Charroó-Ruíz MD MS, María C. Pérez-Abalo MD PhD, María C. Hernández MD, Beatriz Álvarez MD, \\ Beatriz Bermejo MD, Sandra Bermejo MD, Lídice Galán PhD, Lourdes Díaz-Comas PhD
}

\begin{abstract}
INTRODUCTION Studies of neuroplasticity have shown that the brain's neural networks change in the absence of sensory input such as hearing or vision. However, little is known about what happens when both sensory modalities are lost (deaf-blindness). Hence, this study of cortical reorganization in visually-impaired child cochlear implant $(\mathrm{Cl})$ candidates.

OBJECTIVE Assess cross-modal plasticity, specifically cortical reorganization for tactile representation in visually-impaired child $\mathrm{Cl}$ candidates, through study of topography of somatosensory evoked potentials (SEP).

METHODS From April through September 2005, SEP from median and tibial nerve electrical stimulation were studied in 12 visuallyimpaired child $\mathrm{Cl}$ candidates aged $3-15$ years and 23 healthy controls. Following placement of 19 recording electrodes using the International 10-20 System, SEP were recorded and then processed. Topographic maps were obtained for SEP N20 (median nerve) and SEP P40 (tibial nerve), permitting assessment of cortical reorganization by comparing visually-impaired, deaf children's maps with those
\end{abstract}

\section{INTRODUCTION}

Neuroplasticity is defined as the nervous system's ability to change and repair itself after injury.[1] Neuroimaging studies of congenitally deaf persons have shown expansion of intact cortical regions into the brain's unutilized areas. The longer the duration of auditory deprivation, the greater the over-representation of visual stimulation in hearing areas.[2-4] Furthermore, it has been shown that in the congenitally blind, visual cortical areas are activated during linguistic processing via touch.[5] This evidence of cortical reorganization is known as cross-modal plasticity (CMP).

However, this effect has been less studied in dual sensory (hearing and vision) deprivation.[6,7] The term "deaf-blind" as used in the field of dual sensory impairment includes people who are not totally blind or deaf. Osaki et al. published the first study of neuroplasticity in subjects with hearing impairment and vision loss in 2004,[6] followed in 2010 by a paper by Obretenova et al.;[7] both studies were of a single adult subject. Osaki et al. described a pattern of cortical activation detected by magnetoencephalography and positron emission tomography (PET) during tactile presentation of words and non-words that showed more extensive active regions in the brain of the deaf-blind subject.[6] However, expanded cortical activation did not appear to be due in this case to brain reorganization mechanisms described for unisensory loss.[1,8] Rather, Osaki interpreted it as cortical reorganization of preexisting connections since the subject had late-onset hearing and vision loss. Thus, when sensory loss occurred, auditory and visual cortices already had activation patterns resulting from of healthy children by means of visual inspection and statistical comparison using a permutation test.

RESULTS SEP N20 topography was significantly more extensive in visually-impaired child $\mathrm{Cl}$ candidates than in healthy children. An asymmetrical pattern occurred from the expansion of hand tactile activation into the temporal and occipital regions in the left hemisphere on right median nerve stimulation. This did not occur for SEP P40 on tibial nerve stimulation (right and left). Magnitude of expanded SEP N20 response was related to severity of visual impairment and longer duration of dual sensory loss.

CONCLUSIONS Changes in SEP N20 topography are evidence of cross-modal plasticity in visually-impaired child $\mathrm{Cl}$ candidates, appearing to result from a complex interaction between severity of visual impairment and duration of multisensory deprivation.

KEYWORDS Somatosensory evoked potentials, deaf-blind, hearing and vision loss, sensorineural hearing loss, cochlear implants, neuroplasticity, neuroimaging, neurophysiology, fMRI, functional magnetic resonance imaging, positron-emission tomography, PET scan, Cuba appropriate stimuli throughout neurodevelopment, since the subject lost hearing and vision at age 35.[6]

There are few published papers on deaf-blind children, all case descriptions, providing limited information.[9-12] Saeed et al. of the Manchester Cochlear Implant Programme studied the largest sample of deaf-blind subjects: 10, 2 of whom were children.[10] We have not found published papers on neuroplasticity in deafblind children that assess dual sensory deprivation-specifically cortical reorganization of touch in auditory and visual areasaddressing its possible implications for progress or effectiveness of rehabilitation in deaf-blind children who receive a cochlear implant $(\mathrm{Cl})$.

It can be hypothesized that in children with congenital or longstanding hearing and vision loss, the intact sensory modality (touch) could modify its cortical representation and even expand into unutilized areas of the brain; i.e., the auditory and/or visual cortices. Detecting reorganization in the tactile area and elucidating its nature requires techniques with high spatial and temporal resolution (neuroimaging and electrophysiological techniques).[1,8]

This study used event-related potentials, electrophysiological techniques that show neuronal post-synaptic activity and consist of recording electrical events: variations in voltage generated in the structures of the central and/or peripheral nervous system following presentation of a specific stimulus, whether sensory, motor or related to a cognitive task.[13] Since the study involves assessment of tactile representation, somatosensory evoked potentials 
(SEP) were indicated. These reveal responses in the somatosensory pathways, in this case to electrical stimulation of the median and tibial nerves, permitting exploration of the system that mediates somatosensory information through the dorsal column in the spinal cord, from the periphery to the primary somatosensory cortex.[13,14]

No literature was found on cortical SEP response mapping in deaf-blind children. However, published studies of healthy subjects generally locate SEP N20 in the centroparietal region, corresponding to activation of the hand area in the contralateral primary somatosensory cortex; and SEP P40 in the centroparietal region (midline), corresponding to activation of the foot area in the primary somatosensory cortex. The main papers on this topic are those by Kakigi et al.[15,16] Consistency of these evoked responses in healthy subjects supports their choice for use as an objective electrophysiological measure for assessing CMP in visually-impaired child $\mathrm{Cl}$ candidates.

It should be noted that although functional MRI (fMRI) is widely used in studies of neuroplasticity, it was not used in this study. MRI is contraindicated after cochlear implantation[17] and so could not be used in post-Cl followup to assess cortical reorganization following rehabilitation.

The objective of this study was to assess CMP, specifically cortical reorganization for tactile representation, in visually-impaired child $\mathrm{Cl}$ candidates, through SEP topography.

\section{METHODS}

A prospective study was conducted of 12 children aged 3-15 years (mean $9.3 \pm 4.2$; 6 boys, 6 girls) with visual impairment and profound sensorineural hearing loss identified as $\mathrm{Cl}$ candidates, from a total of 19 visually-impaired deaf children assessed by the Cuban Cochlear Implant Group (Table1).

All children studied qualified as $\mathrm{Cl}$ candidates by virtue of having profound bilateral sensorineural hearing loss as measured by severity of deafness[13] (absence of audiometric response at conversational frequencies of $0.5,1.2$ and $4 \mathrm{KHz}$ or audibility threshold of $>90 \mathrm{~dB}$ by electroaudiometry or pure tone audiometry). Degree of vision loss was assessed by ophthalmologic evaluation

Table 1. Characteristics of study cohort of visually-impaired deaf Cuban children

\begin{tabular}{|c|c|c|c|c|c|c|}
\hline \multirow[b]{2}{*}{ Child } & \multirow{2}{*}{$\begin{array}{c}\text { Age } \\
\text { (years) }\end{array}$} & \multirow[b]{2}{*}{ Sex } & \multirow{2}{*}{$\begin{array}{c}\text { Age at onset } \\
\text { of deafness } \\
\text { (years) }\end{array}$} & \multirow{2}{*}{$\begin{array}{l}\text { Severity of } \\
\text { vision loss }\end{array}$} & \multicolumn{2}{|r|}{ Causes } \\
\hline & & & & & Deafness & Vision loss \\
\hline sc013 & 9 & $\mathrm{~F}$ & 0 & MVL & Congenital & Retinitis pigmentosa \\
\hline SC003 & 13 & M & 0 & MVL & Unknown & Unknown \\
\hline sc012 & 3 & M & 0 & MVL & Unknown & Unknown \\
\hline SC004 & 7 & M & 1.3 & MVL & Meningitis & Hereditary \\
\hline SC015 & 4 & $\mathrm{~F}$ & 0 & LV & Hereditary & Hereditary \\
\hline SC014 & 6 & $\mathrm{~F}$ & 0 & LV & Congenital & Retinitis pigmentosa \\
\hline SC016 & 6 & $\mathrm{~F}$ & 0 & LV & Hereditary & Hereditary \\
\hline SC007 & 12 & $\mathrm{~F}$ & 0 & LV & Hereditary & Hereditary \\
\hline SC009 & 14 & $\mathrm{~F}$ & 0.3 & LV & Drug induced & Usher's syndrome \\
\hline SC010 & 15 & M & 2.5 & LV & Drug induced & Glaucoma \\
\hline SC001 & 8 & M & 0 & B & Congenital & Congenital \\
\hline SC005 & 14 & M & 0 & B & Congenital & Hereditary \\
\hline
\end{tabular}

MVL: Mild vision loss LV: Low vision B: Blind following International Council of Ophthalmology criteria,[18,19] including examination of visual acuity (VA), binocular vision and visual field. The sample was grouped into two subgroups: (1) four children with mild vision loss (VA $<0.8$ and $\geq 0.3$ ); and (2) eight children with more severe vision loss, six with low vision (VA $<0.3$ and $\geq 0.05$ ) and two totally deaf-blind (no light perception on clinical ophthalmologic examination).

A control group of 23 healthy children with normal hearing and vision was selected, comparable in age (mean $11 \pm 0.87$ years) and sex to the $\mathrm{Cl}$ candidates. Inclusion criteria for controls were absence of personal neurological disorders, no medications taken on a regular basis, no drugs that could affect the nervous system and a normal physical and neurological exam.

Handedness was assessed; all children in the control group were right-handed as were almost all $\mathrm{Cl}$ candidates, except two lefthanded visually-impaired deaf children.

Median and tibial nerve SEP To map cortical responses for median and tibial nerve SEP, corresponding respectively to activation of hand and foot tactile areas in the primary somatosensory cortex, the TrackWalker program was used with a digital MEDICID-4 (Neuronic SA Cuba) electroencephalograph. A monopolar recording montage was used with the 19 derivations of the 10-20 International System and a linked ear reference. Surface electrodes were used for recording, with impedances kept below $5 \mathrm{~kW}$ during the entire recording. Signals were filtered between 0.5 and $300 \mathrm{~Hz}$, and the sampling frequency was set at $1000 \mathrm{~Hz} .[14,20]$

To evoke somatosensory response, the median and tibial nerves were stimulated on both sides separately with a Neuropack 2 (Nihon Kohden Corporation, Japan) electrical stimulator, coupled to the MEDICID-4. The ground electrode was placed around the middle third of the arm or leg, depending on the nerve being stimulated. The stimulating bar electrode was placed on the wrist for the median nerve and behind the medial malleolus for the tibial nerve, for stimulation with the proximal cathode. An electrical stimulus of $0.1 \mathrm{~ms}$ duration at a frequency of $3 \mathrm{~Hz}$ was used. Intensity was increased gradually until there was clearly perceived movement of the thumb on median nerve stimulation and of the big toe on tibial nerve stimulation.[19] Each nerve was stimulated for 10 minutes.

All recordings were made in a room with low ambient noise and controlled temperature (never below $24^{\circ} \mathrm{C}$ ). Body temperature was taken during recording. None of the subjects presented fever or hypothermia. During the procedure, subjects rested in a supine position with eyes closed, as relaxed as possible. With the two youngest visually-impaired deaf children (Table 1), the sedation (midazolam at a dose of $0.25-0.5 \mathrm{mg} / \mathrm{kg}$ ) they received for ear neuroimaging studies was exploited to conduct our study in the same session, since sedation does not affect SEP N20 and SEP P40 evoked responses.[21]

Assessment of median and tibial nerve SEP Brain electrical activity recordings were 
assessed offline to extract SEP and thus evaluate N20 and P40 components corresponding to the cortical responses on stimulation of median and tibial nerves, respectively. Segments were recorded starting $20 \mathrm{~ms}$ pre-stimulus; evoked signals were plotted in analysis windows for a total time of 70 and $120 \mathrm{~ms}$ for median and tibial nerves, respectively. These segments (1000 windows per nerve) were averaged to obtain SEP.

Topographic maps were obtained for each individual SEP recording, along with average maps for each nerve (median and tibial) from both sides for both groups of children. These were plotted using a peak percentage scale in which $50 \%$ of the value of the maximum amplitude among all derivations is taken as the maximum value of the scale.[22]

A nonparametric permutation test was used to compare SEP topography between the two groups of children,[23] testing the hypothesis of null difference between the two groups in mean amplitude vectors (signal voltage) formed by each derivation of SEP recordings. One thousand permutations were done in the 15-25 ms and 35-45 ms post-stimulus time intervals for median and tibial nerve SEP recordings, respectively, using a significance level of $p \leq 0.05$. Next, SEP N20 topographic maps were assessed considering duration of hearing loss and duration and severity of vision of visual deficit.

Ethical considerations Prior to the study, parents and children able to understand were given an explanation of what the test entailed and provided written informed consent for participation. The study protocol was approved by the ethics committees of the Marfán Pediatric Hospital and the Cuban Neuroscience Center.

\section{RESULTS}

Figure 1 shows typical SEP recordings obtained from electrical stimulation of the median (a) and tibial (b) nerves in a $\mathrm{Cl}$ candidate. Note the great similarity between the two subaverages of signals obtained in all recorded derivations. From visual inspection of the recording, it was possible to identify the N20 and P40 cortical component in each recording.

Scalp topography of SEP N20 and P40 In these Cl candidates, there was an expansion in SEP N20 topography corresponding to representation of activation of the hand's tactile area (Figure $2 a)$. This representation was asymmetrical, since in these children the number of sites activated in the left hemisphere-the response evoked by stimulation of the right median nerve-was greater, encompassing sites C3, P3, T3, T5, and O1. In these children, activation extended to other sites that normally process sensory input from other modalities, such as auditory (T3, T5) and visual (O1). SEP P40 topographic maps for both groups of children are shown in Figure $2 \mathrm{~b}$. Note that activation was quite similar in both groups, and was located on the posterior midline (Pz recording site), which represents the exclusive activation of the foot area in the primary somatosensory cortex with tibial nerve stimulation.

The permutation test found activation of recording sites $\mathrm{C} 3$, P3, T3, T5 and $\mathrm{O} 1$ to be significantly different between the two groups of children for right ( $p=0.03)$, but not for left median nerve response, SEP N20 ( $p=0.21)$ (Figure $2 c)$. In contrast, the permutation test for SEP P40 did not find statistically significant
Figure 1: Somatosensory evoked potential recordings in a Cuban child cochlear implant candidate

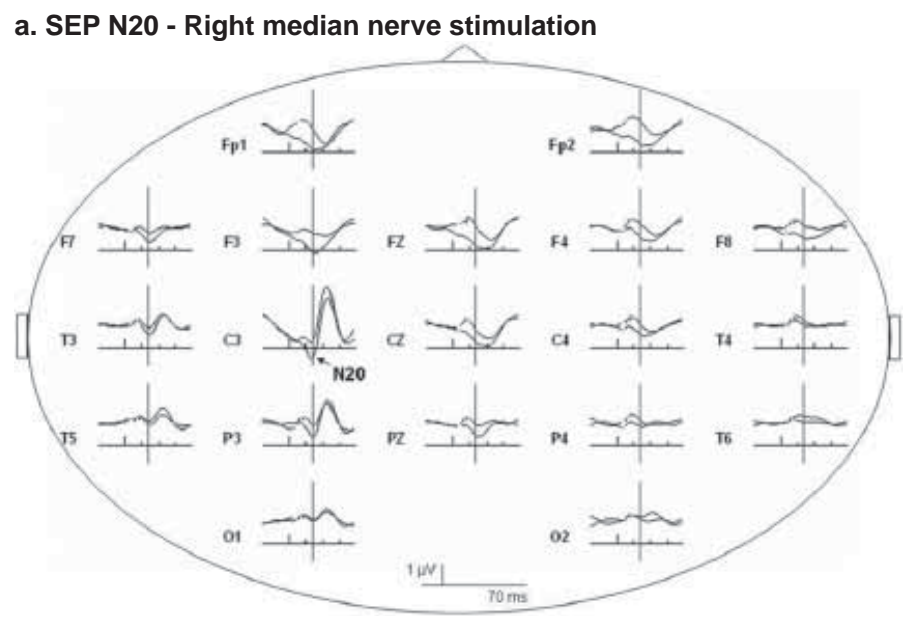

b. SEP P40 - Left tibial nerve stimulation

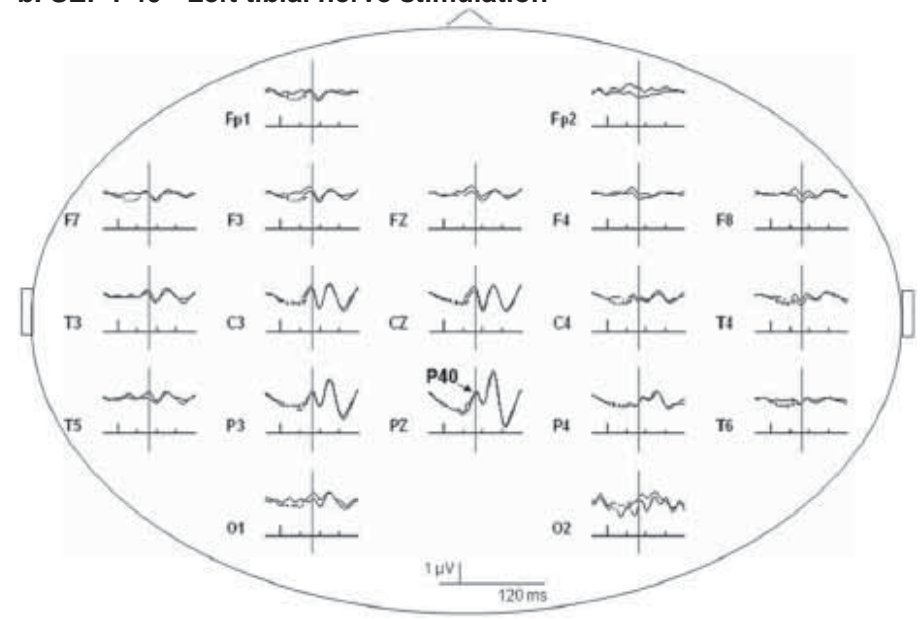

Recordings from 19 scalp electrodes following stimulation of right median (a) and left tibial (b) nerves in deaf subject with low vision. Vertical bars indicate first main deflection in each SEP. Representative wave forms recorded were clearly identified. N20 (a) and P40 (b) scalp far-fields are indicated in $\mathrm{C} 3$ and $\mathrm{Pz}$ traces, respectively, where these components reach maximum amplitude.

differences between the two groups at any of the 19 recording sites ( $p=0.78$ for right and $p=0.31$ for left tibial nerve).

SEP N20 topography changes in relation to duration of deafness and severity of vision loss Only SEP N20 topography was analyzed since SEP P40 did not show changes in topography between $\mathrm{Cl}$ candidates and healthy children. SEP N20 topography changes by duration of deafness and severity of vision loss are shown in Figure 3. Changes were minimal in children with a shorter duration of hearing loss ( $\leq 6$ years since onset of deafness), while children with deafness of $\geq 7$ years presented evident SEP N20 topography changes with greater extension into temporal, parietal and occipital regions (Figure 3a). These regions do not correspond to those activated with median nerve stimulation in control subjects, since they are where auditory and visual sensory input are normally processed. There was greater activation of the parietal region (where tactile input from the hand is represented in the primary somatosensory cortex) in $\mathrm{Cl}$ candidates than in the control group. 
Figure 2: Grand-average SEP N20 (a) and P40 (b) topographic maps, and results of permutation test of SEP N20 topography (c) of visually-impaired deaf children and control group

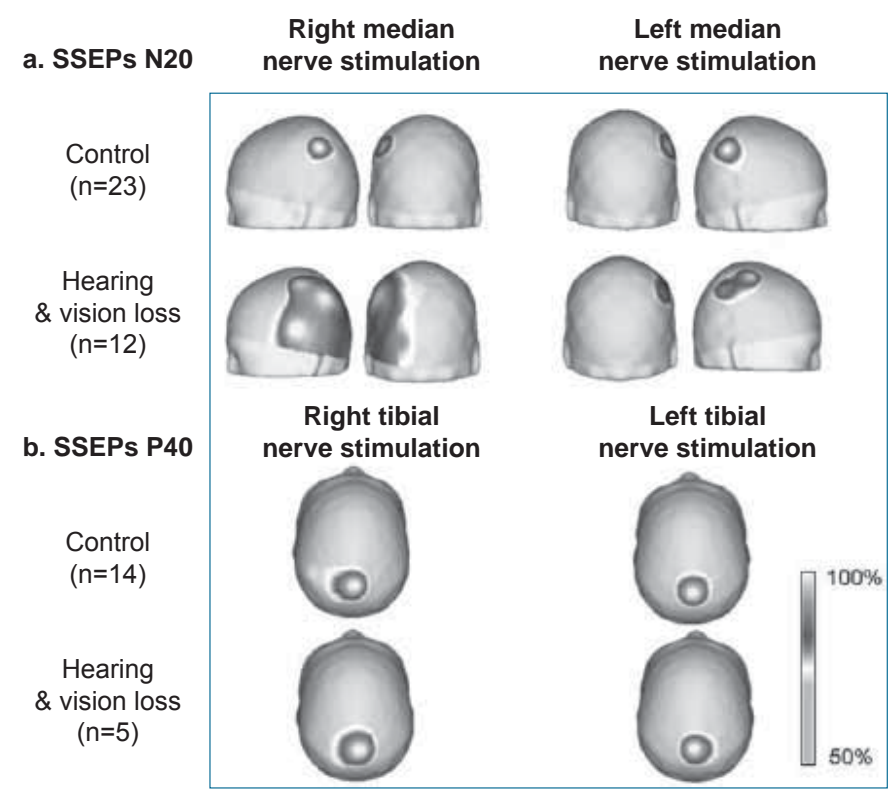

(available in color online at http://www.medicc.org/mediccreview/charroo.html)

\section{c. Left Hemisphere}

Overall Probability $p=0.03$

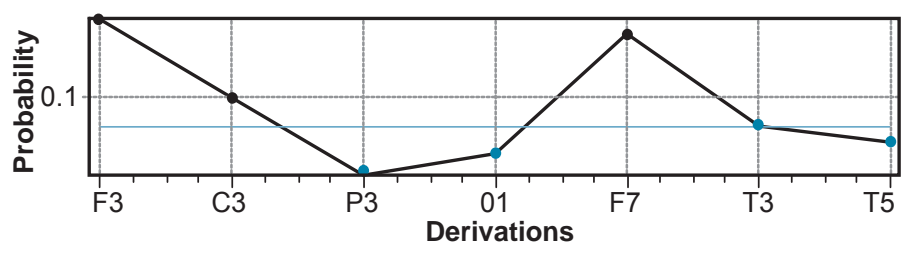

Right Hemisphere

Overall Probability $p=0.21$

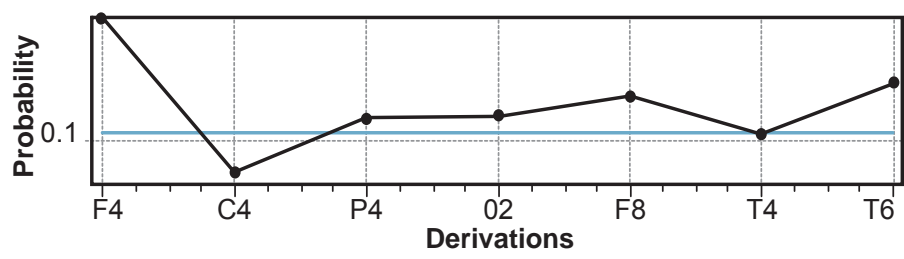

Expansion of SEP N20 response did not occur in children with mild vision loss but was pronounced in low-vision and totally deafblind children (Figure 3b).

The overall effect of vision loss severity and duration of auditory deprivation on SEP N20 topography is illustrated in Figure 4. In children with shorter duration of deafness and less severe vision loss, SEP N20 topography remained localized in the central region; there was a positive slope relationship between duration and degree of localization; i.e., in children with longer-standing deafness and more severe vision loss, SEP N20 topography became more extensive, eventually occupying the entire centralposterior region of the hemisphere contralateral to the stimulated median nerve. This positive slope relationship was not as steep in relation to vision loss severity.
Figure 3: SEP N20 Topography by duration of deafness and severity of vision loss

Right median nerve. Left hemisphere.

a. Duration of deafness

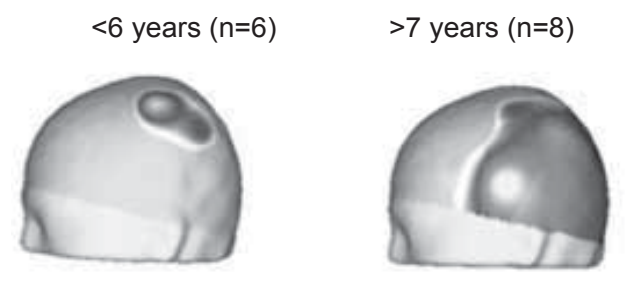

b. Severity of vision loss

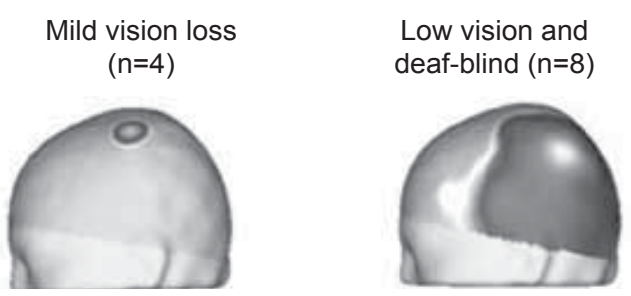

(available in color online at http://www.medicc.org/mediccreview/charroo.html)

\section{DISCUSSION}

This study of SEP topography from electrical stimulation of median (SEP N20) and tibial (SEP P40) nerves provides the first evidence using electrophysiological techniques of reorganization of tactile cortical areas as an effect of CMP in children with concurrent hearing and vision loss.

Our findings indicate that there is over-representation in SEP N20 topography in children with hearing and vision loss, which is selective for the response obtained from median nerve stimulation and occurs asymmetrically, with an expansion of activated areas into the left temporal, parietal and occipital regions, normally intended for processing other sensory modalities (auditory input in the temporal region, visual information in the occipital region). In contrast, the parietal region, which normally processes somatosensory information, was activated with tactile stimulation as expected, but more strongly in $\mathrm{Cl}$ candidates than in control subjects. This reorganization was greater in subjects with longer duration of hearing and vision loss and in those whose vision loss was very severe from an early age.

The regularity of SEP $\mathrm{N} 20$ and P40 topographic patterns in healthy children, both in individual and group maps, is consistent with reports from other authors[15,16] and therefore supports their clinical usefulness with this approach; i.e., employing them to assess CMP by demonstrating the marked difference in SEP N20 topography between visually-impaired child $\mathrm{Cl}$ candidates and healthy children.

The only two published studies of neuroplasticity in adult subjects with hearing and vision loss used neuroimaging and/or neurophysiological techniques. By examining patterns of cortical activation in response to linguistic stimulation (words vs. non-words) presented by touch, these authors found an amplification of the number of sites or regions activated in a deaf-blind subject com- 
Figure 4: SEP N20 topography in visually-impaired cochlear implant candidates by site of maximum amplitude, vision loss severity and duration of deafness

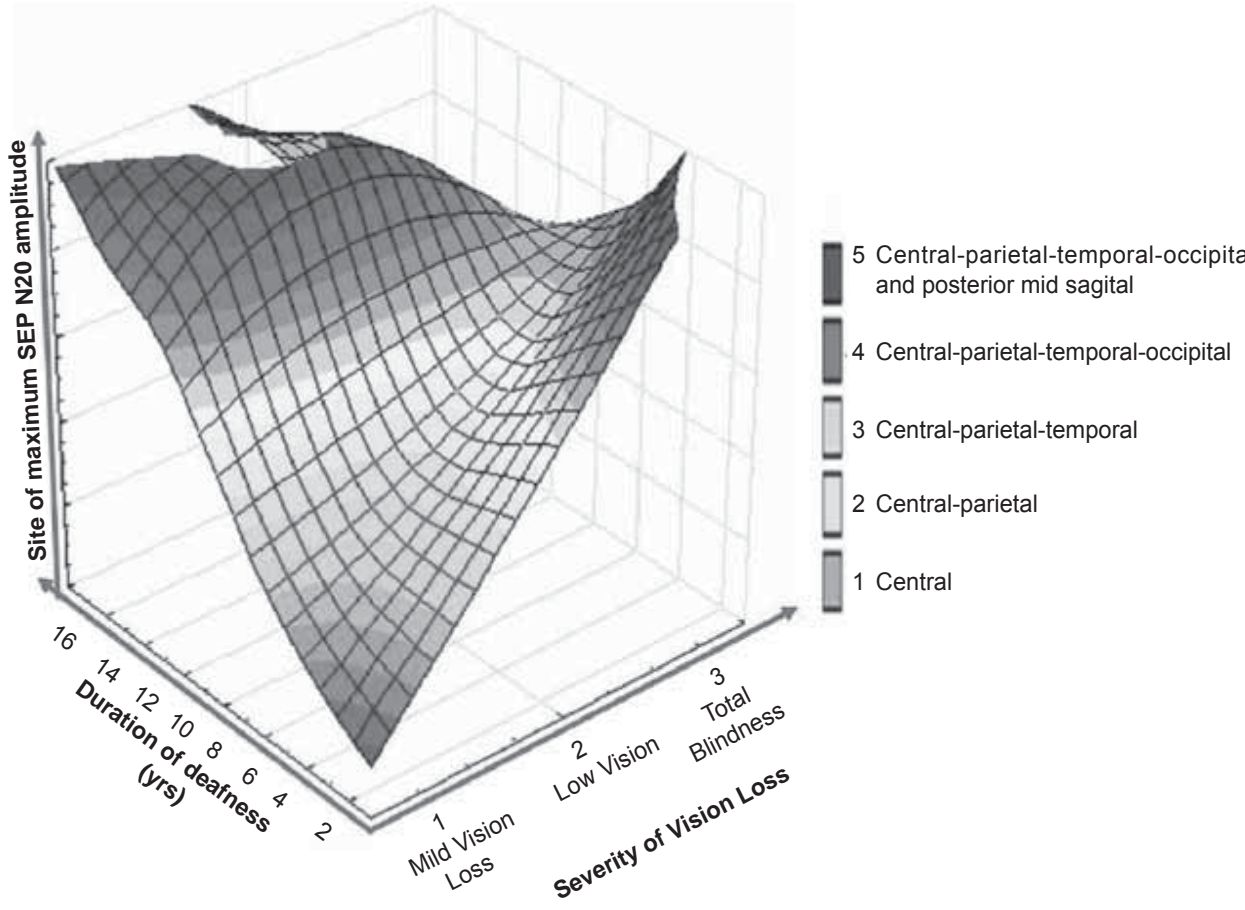

(available in color online at http://www.mediccreview/charroo.html)

pared to six healthy control subjects.[6,7] These findings were interpreted as indication of greater demand on resources for linguistic and semantic processing.[6]

Although there are considerable methodological differences between this study and Osaki's,[6] our topographic maps showed a significantly different activation pattern in children with dual sensory deprivation that was not observed in any of the control group children. The selective and asymmetric difference in SEP N20 was predominant in the left hemisphere. This provides strong evidence of reorganization of the tactile area due to multisensory deprivation, constituting the first published evidence of its kind obtained using an electrophysiological technique (SEP of median and tibial nerves) in children with multisensory deprivation.

The effects of sensory deprivation occurred precisely during the window of greatest brain plasticity; i.e., during the critical period of neural development.[24-26] Hearing and vision loss was detected early in all cases, at birth or around the age of three months when they were assessed by Cuba's Hearing Screening Program. Only two children became deaf after three months of age, both before three years, thus before language development was completed. In our opinion, early dual sensory loss facilitated and produced extensive cortical reorganization for touch, which was not observed in Osaki's adult patient,[6] in whom neural networks for auditory and visual processing were fully formed by the time dual deprivation occurred.

It is unlikely that our findings can be explained as amplification of pre-existing connections in the brain, considering that expansion of SEP N20 topography was not observed in any of the control group children. In contrast, although based on SEP, our results are more consistent with Obretenova's, using fMRI, describing a single adult subject with hearing and vision loss (prelingually deaf-blind) in whom tactile communication (braille) was associated with extensive activation of a cortical network that included occipital, temporal and frontal regions.[7]

The first published studies on cortical reorganization with single sensory deprivation-auditory or visual-used evoked potentials. For example, Neville et al. reported changes in evoked visual response in congenitally deaf persons and interprfeted it as a neuroplastic change, in which visual input invades unused areas of the auditory cortex.[27]

These finding were later confirmed in studies of subjects with single sensory deprivation (auditory or visual) using neuroimaging techniques with greater spatial resolution (fMRI and PET),[5,2830] which demonstrated extensive cerebral reorganization in cortical areas, showing how auditory areas of the brain are activated by visual stimuli in deaf persons,[3] while the visual cortex is activated by somatosensory and auditory stimuli in blind persons. $[5,28,31,32]$

Our findings could be ascribed to this form of neuroplasticity, CMP. This would then be confirmation of results previously obtained in subjects with single sensory deprivation (deaf or blind), well described in review articles.[1,8] In general, these studies have used more complex linguistic stimuli-sign language and braillewhich in the case of blind persons also indirectly involves touch. $[2,27,33]$ None has assessed simple tactile stimuli, nor studied children with hearing and vision loss.

A possible interpretation of our results could be that with simultaneous loss of hearing and vision at very early stages of neural development, touch acquires a more important role in children's communication with their surroundings. When learning sign language and/or braille (or another communication system using touch), these children make very intense use of their hands. They also explore their surroundings with their hands, which we observed in the clinical neurophysiology laboratory while they were waiting to be seen and while they were inpatients in the Cochlear Implant Unit. This may explain the fact that topographic changes are selective for SEP N20 and not for SEP P40.

Although these findings are descriptive results for only 12 visuallyimpaired deaf children, we consider them to be valid as they are representative of the 19 visually-impaired deaf children assessed by the Cuban Cochlear Implant Group in 2005. While one might consider the sample size small for supporting the results, we hold that, given the difficulty of studying visually-impaired deaf children,[9-12] the cohort studied is actually rather substantial. It is important to underscore that results were consistent in the $12 \mathrm{Cl}$ 
candidates compared to healthy children; there was no expansion of SEP N20 response in the control group, but this occurred in every $\mathrm{Cl}$ candidate and in the grand-average map.

However, it remains to be assessed to what extent SEP N20 topography changes observed in children with hearing and vision loss is specific to deaf-blindness as an entity or if on the contrary is the same effect described for single sensory deprivation (visual or auditory). New SEP N20 topographic studies are needed of hand representation area in the primary somatosensory cortex.

The asymmetric expansion of SEP N20 predominant in the left hemisphere, where the right hand is represented, is physiologically congruent, precisely because the sample was almost entirely right-handed, since these children make extensive use of their hands for communicating and for interacting with their surroundings, and, with the exception of two children, it is their dominant hand.

This study undoubtedly contributes to the field of $\mathrm{Cl}$ in children with multiple disabilities, since few studies have been done of $\mathrm{Cl}$ in children with hearing and vision loss, and these are limited to case presentations describing progress made by implanted children.[9-12] It has been demonstrated that $\mathrm{Cl}$ is less effective if the child is implanted late, when there is greater cortical reorganization in the auditory cortex. $[1,34]$ It has been posited that implant effectiveness is greater in deaf-blind persons, even with long duration.[10] This can be interpreted as a sign that touch does not expand to the same extent and/or does not interfere to the same degree with auditory processing.

A limitation of this study was that it did not assess competition between intact somatosensory input and residual vision. We observed that touch does expand into regions responsible for processing auditory and visual information in visually-impaired deaf children. However, during analysis and interpretation of the results, we realized that the limitations of considering deaf-blindness as a disability involving the loss of both senses without taking into account that vision loss is not necessarily total.[35]

When dealing with children who have profound bilateral sensorineural deafness in common, there is absolutely no possibility of exploring cortical activation via this route. In contrast, given that these children presented differences in vision loss severity, we have still to explore their cortical response in terms of CMP if given visual in addition to tactile stimuli. Thus, reorganization of touch vs. vision remains to be assessed in children with profound bilateral sensorineural hearing loss and residual vision.

Several questions of scientific interest should be answered in future studies: What occurs in visually-impaired deaf children with residual vision? How does touch compete with the input of visual information through the residual vision and what is its interaction with the auditory area? Is the observed SEP N20 over-representation exclusive to the visually-impaired deaf, or on the contrary, is it also present in those who are only deaf or blind?

The study was able to describe the ability achieved by sense of touch in visually-impaired deaf children eligible for $\mathrm{Cl}$. A cohort of children has been identified in whom it will be possible to reassess cortical reorganization once the auditory canal becomes responsive through $\mathrm{Cl}$ and after they have received rehabilitation therapy. We therefore believe that this study will contribute to research on neuroplasticity to describe post-Cl brain reorganization, once these children have developed verbal communication-of course with certain limitations. By then, they will no longer be using their hands as much for communication and the auditory cortex will be receiving appropriate sensory input.

The study sheds light on some aspects of neuroplasticity in visually-impaired child $\mathrm{Cl}$ candidates that can be addressed in future research. It was facilitated by the priorities of the Cuban health system and its national Cochlear Implant Program, which is primarily focused on children and gives particular priority to deaf-blind children.[36] It is said that deaf-blind children do not generally achieve great progress in word production after $\mathrm{Cl}$, but do attain marked improvement in their emotional state, attention span and interaction with their environment.[37]

Finally, although this study did not examine neural and synaptic mechanisms that could provide supporting evidence of SEP $\mathrm{N} 20$ topography changes in $\mathrm{Cl}$ candidates, we could hypothesize about the phenomena involved by referring to basic experimental findings regarding neuroplastic changes in sensory systems as an effect of single sensory deprivation (auditory or visual) discussed in review articles on the topic.[35,38]

In summary, neuroplasticity in deaf-blind children requires further study. Post-Cl assessment of deaf-blind children using electrophysiological techniques, in this case SEP N20, will be useful to describe changes or lack thereof in cortical reorganization during auditory rehabilitation.

\section{CONCLUSIONS}

In visually-impaired child $\mathrm{Cl}$ candidates, a significant change was found in SEP N20 topography (hand representation area) that was selective for this component and not for SEP P40 (foot representation area) in comparison to a control group of healthy children, with expansion of activation into the left temporal, parietal and occipital regions. This finding could be attributed to crossmodal plasticity, described for single sensory deprivation (auditory or visual).

Extent of change in SEP N20 topography on right median nerve stimulation was related to coexistence of very severe visual and auditory impairment from early ages and to dual sensory deprivation of long duration. This is the first published evidence of cortical reorganization using SEP in visually-impaired child $\mathrm{Cl}$ candidates.

Everything we can do for the wellbeing of deaf-blind children-for their health, education and social integration-constitutes a high priority and, at the same time, a considerable challenge due to the nature of their condition.

\section{ACKNOWLEDGMENTS}

The authors are grateful to the specialists in the Cuban Cochlear Implant Group as well as to the children and their parents, without whose help this study would not have been possible. - 1 - 


\section{REFERENCES}

1. Bavelier D, Neville H. Cross-modal plasticity: where and how? Nat Rev Neurosci. 2002 Jun;3(6):443-52.

2. Neville HJ, Bavelier D, Corina D, Rauschecker J, Karni A, Lalwani A, et al. Cerebral organization for language in deaf and hearing subjects: biological constraints and effects of experience. Proc Natl Acad Sci USA. 1998 Feb 3;95(3):922-9.

3. Bavelier D, Tomann A, Hutton C, Mitchell T, Corina D, Liu G, et al. Visual attention to the periphery is enhanced in congenitally deaf individuals. J Neurosci. 2000 Sep 1;20(17):RC93.

4. Finney E, Fine I, Dobkins K. Visual stimuli activate auditory cortex in the deaf. Nat Neurosci. 2001 Dec;4(12):1171-3.

5. Sadato N, Pascual-Leone A, Gramfman J, Ibañez V, Deiber MP, Dold G, et al. Activation of the primary visual cortex by Braille reading in blind subjects. Nature. 1996 Apr 11;380(6574):526-8.

6. Osaki Y, Doi K, Takasawa M, Noda K, Nishimura $H$, Ihara $A$, et al. Cortical processing of tactile language in a postlingually deaf-blind subject. Neuroreport. 2004 Feb 9;15(2):287-91.

7. Obretenova S, Halko MA, Plow EB, PascualLeone A, Merabet LB. Neuroplasticity associated with tactile language communication in a deafblind subject. Front Hum Neurosci. 2010 Jan 4;3:60.

8. Merabet LB, Pascual-Leone A. Neural reorganization following sensory loss: the opportunity of change. Nat Rev Neurosci. 2010 Jan;11(1):4452.

9. Chute PM, Nevis ME. Cochlear implants in people who are deaf-blind. J Visual Impairm Blindness. 1995 May-Jun;89(3):297-301.

10. Saeed SR, Ramsden RT, Axon PR. Cochlear implantation in the deaf-blind. Am J Otol. 1998 Nov;19(6):774-7.

11. El-Kashlan HK, Boerst A, Telian SA. Multichannel cochlear implantation in visually impaired patients. Otol Neurotol. 2001 Jan;22(1):53-6.

12. Filipo R, Bosco E, Mancini P, Ballantyne D. Cochlear implants in special cases: deafness in the presence of disabilities and/or associated problems. Acta Otolaryngol Suppl. 2004 May;(552):74-80.

13. Charroó L, Hernández R, Pérez-Abalo M, Machado C, Galán L, Aznielle T. Potenciales Evocados. Técnicas neurofisológicas y aplicaciones clínicas. Havana: Editorial Academia; 2001. p. 1-25 and 77-114. Spanish.

14. Standards for short latency somatosensory evoked potentials. Bloomfield (US): American Clinical Neurophysiology Society; 2006.

15. Kakigi R, Shibasaki H. Effects of age, gender, and stimulus side on the scalp topography of somatosensory evoked potentials following median nerve stimulation. J Clin Neurophysiol. $1991 \mathrm{Jul} ; 8(3): 320-30$.

16. Kakigi R, Shibasaki H. Effects of age, gender, and stimulus side on the scalp topography of somatosensory evoked potentials following posterior tibial nerve stimulation. J Clin Neurophysiol. 1992;9(3):431-40.

17. MRIsafety.com [Internet]. California (US): Shellock R\&D Services, Inc; c2012. Cochlear Implants; [cited 2002 Apr 27]. Available from: http://mrisafe ty.com/safety article.asp?subject $=22$.

18. Colenbrander A. Visual standards. Aspects and ranges of vision loss, with emphasis on population surveys [Internet]. Sydney: International Council of Ophthalmology; 2002 April. Resolution adopted by the International Council of Ophthalmology; [cited 2011 Mar 7]; p 2. Available from: www.icoph.org/pdf/visualstandardsreport.pdf.

19. Colenbrander A. Visual standards. Aspects and ranges of vision loss, with emphasis on population surveys [Internet]. Sydney: International
Council of Ophthalmology; 2002 Apr [cited 2002 Apr 27]. 33 p. Available from: http://www.icoph .org/downloads/visualstandardsreport.pdf.

20. Charroó L, Aznielle T, Borrego M, Antelo JA, Díaz-Comas L, Suárez A, et al. Adquisición de la respuesta cortical del Potencial Evocado Somatosensorial del nervio tibial con múltiples derivaciones de registro. Rev Ing Electrónica, Automática y Comunicaciones. 2005;16(2):3944. Spanish.

21. Chiappa KH, Hill RA. Short-latency somatosensory evoked potentials: Interpretation. In: Chiappa $\mathrm{KH}$, editor. Evoked Potentials in Clinical Medicine. 3rd ed. New York: Lippincott-Raven; 1997 Mar 24. p. 341-400.

22. Díaz-Comas L, Borrego M, Bobes MA, Galán L, Carbonell F. Sistema para la obtención y análisis de Potenciales Evocados Endógenos de alta densidad. Memorias del I Congreso Internacional de Biolnformática 2004. Havana: Ministry of Science, Technology and Environment (CU); 2004. Spanish.

23. Galán L, Biscay R, Rodríguez JL, Carbonell F, Valdés P. Testing topographic differences between event related brain potentials by using non-parametric combinations of permutation tests. Electroencephalogr Clin Neurophysiol. 1997 Mar;102(3):240-7.

24. Nikolopoulos TP. Outcomes and predictors in cochlear implantation [doctoral thesis]. [Nottingham (UK)]: University of Nottingham; 2000. p. 138 and p. 166.

25. Gilley PM, Sharma A, Mitchell TV, Dorman MF. The influence of a sensitive period for auditory-visual integration in children with cochlear implants. Restor Neurol Neurosci. 2010;28(2):207-18.

26. Tomblin JB, Barker BA, Spencer LJ, Zhang X, Gantz BJ. The effect of age at cochlear implant initial stimulation on expressive language growth in infants and toddlers. J Speech Lang Hear Res. 2005 Aug;48(4):853-67.

27. Neville HJ, Lawson D. Attention to central and peripheral visual space in a movement detection task: an event-related potential and behavioural study. II. Congenitally deaf adults. Brain Res. 1987 Mar 10;405(2):268-83.

28. Sadato $N$, Okada T, Honda M, Yonekura $Y$. Critical period for cross-modal plasticity in blind humans: a functional MRI study. Neuroimage. 2002 Jun;16(2):389-400

29. Stevens AA, Weaver KE. Functional characteristics of auditory cortex in the blind. Behav Brain Res. 2009 Jan 3;196(1):134-8

30. Auer ET Jr, Bernstein LE, Sungkarat W, Singh M. Vibrotactile activation of the auditory cortices in deaf versus hearing adults. Neuroreport. 2007 May 7;18(7):645-8.

31. Collignon $\mathrm{O}$, Lassonde $\mathrm{M}$, Lepore $\mathrm{F}$, Bastien $\mathrm{D}$, Veraart C. Functional cerebral reorganization for auditory spatial processing and auditory substitution of vision in early blind subjects. Cereb Cortex. 2007 Feb;17(2):457-65.

32. Voss P, Gougoux F, Zatorre RJ, Lassonde M, Lepore F. Differential occipital responses in early- and late-blind individuals during a soundsource discrimination task. Neuroimage. 2008 Apr 1;40(2):746-58.

33. Neville HJ, Schmidt A, Kutas M. Altered visualevoked potentials in congenitally deaf adults. Brain Res. 1983 Apr 25;266(1):127-32.

34. Sharma A, Dorman MF, Spahr AJ. A sensitive period for the development of the central auditory system in children with cochlear implants: implications for age of implantation. Ear Hear. 2002 Dec;23(6):532-9.

35. Nikolopoulos TP, Lioumi D, Stamaki S, O'Donoghue GM. Evidence based overview of ophthalmic disorders in deaf children: a literature update. Otol Neurotol. 2006 Feb 27;27(2 Suppl 1):S1-24.

36. Giraldo G. Breaking the sound barrier: Cuba's Cochlear Implant Program. MEDICC Rev. 2010 Winter;12(1):13-6.

37. Vlastarakos PV, Proikas K, Papacharalampous G, Exadaktylou I, Mochloulis G, Nikolopoulos TP. Cochlear implantation under the first year of age-The outcomes. A critical systematic review and meta-analysis. Int $\mathrm{J}$ Pediatr Otorhinolaryngol. 2010 Feb;74(2):119-26.

38. Moller C. Deafblindness: living with sensory deprivation. Lancet. 2003 Dec;362 Suppl:S46-7.

\section{THE AUTHORS}

Lidia E. Charroó-Ruíz (Corresponding author: lidia@cneuro.edu.cu), clinical neurophysiologist. Associate professor, Cuban Neuroscience Center (CNC), Havana, Cuba.

María C. Pérez-Abalo, clinical neurophysiologist, CNC, Havana, Cuba.

María C. Hernández Cordero, clinical neurophysiologist, CNC, Havana, Cuba.

Beatriz Álvarez Rivero, ophthalmologist, Marfán Pediatric Teaching Hospital, Havana, Cuba.

Beatriz Bermejo Guerra, speech therapist and speech pathologist, La Pradera International Health Clinic, Havana, Cuba.

Sandra Bermejo Guerra, Hearing Center, Marfán Pediatric Teaching Hospital, Havana, Cuba.

Lídice Galán García, mathematician, CNC, Havana, Cuba.

Lourdes Díaz-Comas, mathematical cybernetics specialist, CNC, Havana, Cuba.

Submitted: November 1, 2010

Approved for publication: April 17, 2012

Disclosures: None

\section{Erratum}

Page 26, in the legend for Figure 2 (both a and b), the second group label should read: "Hearing \& vision loss." 